\title{
Isometric thermogenesis at rest and during movement: a neglected variable in energy expenditure and obesity predisposition
}

\author{
A. G. Dulloo*; J. L. Miles-Chan; J.-P. Montani and Y. Schutz
}

${ }^{1}$ Department of Medicine, Division of Physiology, University of Fribourg, Fribourg, Switzerland

Address for correspondence: Professor AG Dulloo, Department of Medicine/Physiology, University of Fribourg, Chemin du Musée 5, CH 1700 Fribourg, Switzerland.

E-mail: abdul.dulloo@unifr.ch

\begin{abstract}
Summary
Isometric thermogenesis as applied to human energy expenditure refers to heat production resulting from increased muscle tension. While most physical activities consist of both dynamic and static (isometric) muscle actions, the isometric component is very often essential for the optimal performance of dynamic work given its role in coordinating posture during standing, walking and most physical activities of everyday life. Over the past 75 years, there has been sporadic interest into the relevance of isometric work to thermoregulatory thermogenesis and to adaptive thermogenesis pertaining to body-weight regulation. This has been in relation to (i) a role for skeletal muscle minor tremor or microvibration - nowadays referred to as 'resting muscle mechanical activity' - in maintaining body temperature in response to mild cooling; (ii) a role for slowed skeletal muscle isometric contraction-relaxation cycle as a mechanism for energy conservation in response to caloric restriction and weight loss and (iii) a role for spontaneous physical activity (which is contributed importantly by isometric work for posture maintenance and fidgeting behaviours) in adaptive thermogenesis pertaining to weight regulation. This paper reviews the evidence underlying these proposed roles for isometric work in adaptive thermogenesis and highlights the contention that variability in this neglected component of energy expenditure could contribute to human predisposition to obesity.
\end{abstract}

Keywords: Adaptive thermogenesis, spontaneous physical activity, weight regulation.

\section{Introduction}

According to the latest edition of the Oxford Dictionary of Food and Nutrition (1), the term isometric thermogenesis as applied to human energy expenditure (EE) refers to 'heat production as a result of increased muscle tension without performing any physical work'. While this definition is in line with those of exercise physiologists and nutritionists in the field of human energy metabolism and physical activity (2-4), it should be emphasized that physical activity is often used synonymously with 'work' which has a strict definition in physics, namely, work performed on the environment, i.e. force $\mathrm{x}$ distance. The net efficiency of muscular work is low ( 25\%) during dynamic work, which involves principally a change in muscle length (5), but is much lower (tending towards zero) for isometric or static work because this type of contraction causes mostly a change in tension with little or no change in length such that there is little or no work performed on the environment. Thus, unlike contracting muscles that produce heat because of their inefficiencies, tensed muscles are simply fully thermogenic; the multiple expressions of isometric thermogenesis are depicted in Fig. 1.

Most physical activities, however, are neither purely dynamic nor purely static but consist of both dynamic 


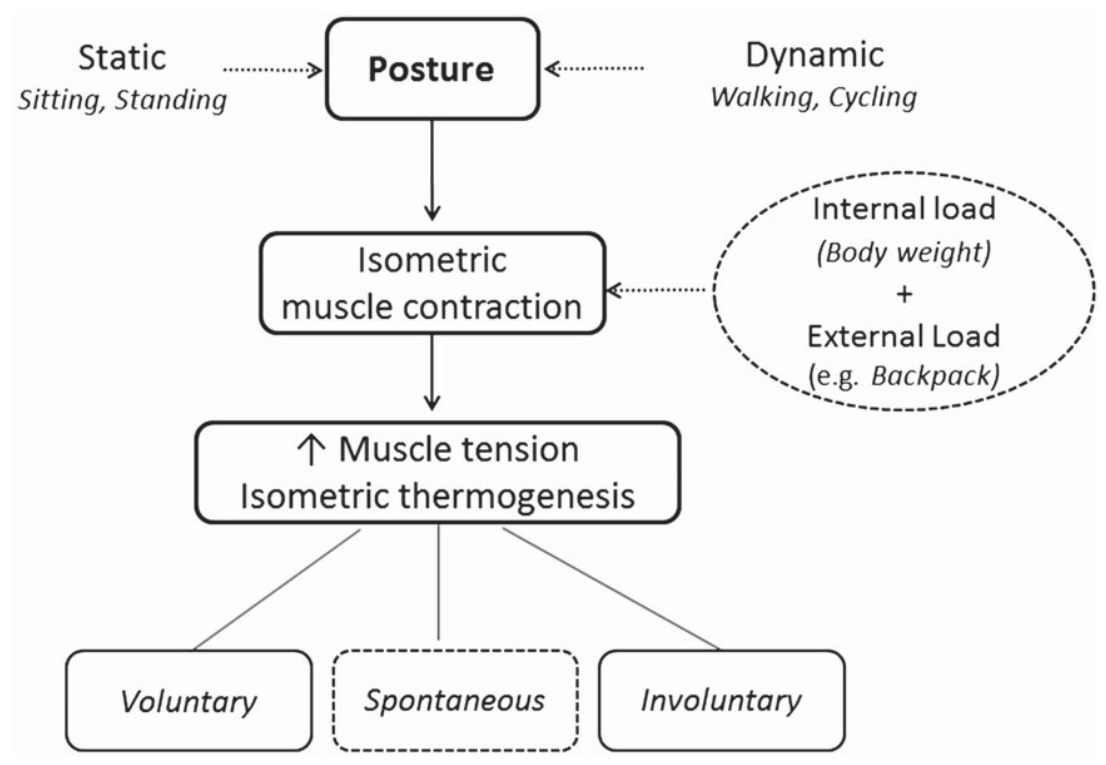

Figure 1 Multiple expressions of isometric thermogenesis in humans. Isometric muscle contraction for posture maintenance can involve skeletal muscle in the upper body, lower body and in the trunk. Its nature can be classified as voluntary, involuntary and spontaneous. The magnitude of internal and external load (if any) influences muscle contraction and hence isometric thermogenesis.

(especially concentric) and static (isometric) muscle actions, with one often being predominant over the other. For example, walking, running, cycling and swimming are physical activities that are predominantly dynamic, but there is also an isometric component; e.g. increased muscle tension to keep a balanced posture while walking (6), increased muscle tension in the trunk and legs while swimming or in the trunk and arms while pedalling on a bicycle. Conversely, while the maintenance of body posture, holding and carrying a load, pushing heavy weights, or contracting muscles against fixed objects are predominantly isometric, they are often intertwined with dynamic work, e.g. walking while carrying a load (Fig. 2).

Consequently, although data on EE during isometric muscle action are scarce $(2,3)$ and the exact contribution of isometric work to daily EE is difficult, if not impossible, to quantify, there is increasing evidence that it has relevance to both energy balance and thermal balance. Indeed, during the past 75 years, sporadic interest into the role of muscle tension (and hence isometric thermogenesis) in body

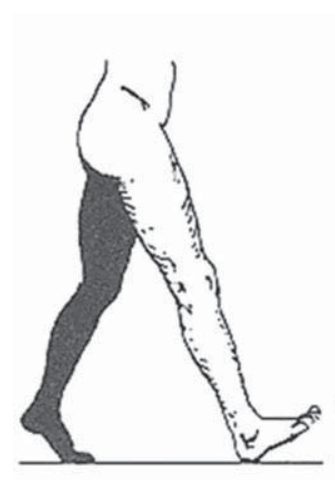

1.

Heelstrike

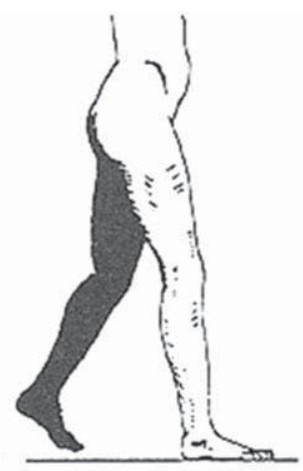

2.

Footflat

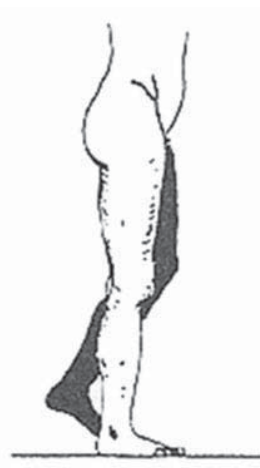

3.

Midstance

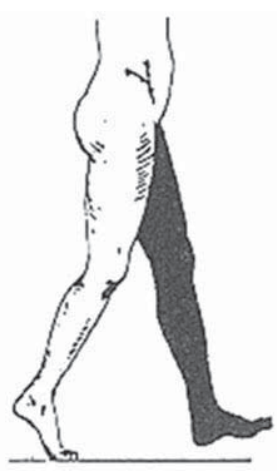

4.

Pushoff

Figure 2 Isometric thermogenesis during walking across the stance component of the gait cycle. In considering only the 'stance' component ( 60\%) of the gait cycle during walking, it should be emphasized that walking is a purposeful disturbance in body equilibrium during which alternating leg displacement sustains body weight through increased muscle tone and hence isometric thermogenesis. By decomposing the lower leg movements over a small time window, it can be observed that during the dynamic pattern of movements, there is a component of isometric contraction of short duration. Walking indeed also involves an isometric component during transitional phases that is associated with dynamic work. In the gait cycle at the end of the 'heelstrike', the pressure exerted on the ground is equal to the resistance on the ground so that isometric contraction occurs. At 'midstance', the isometric force is maximum. Adapted from Reference (6). 
temperature homeostasis, as well as in relation to body weight and body composition regulation, has centred upon the following areas:

1. a role for skeletal muscle minor tremor or microvibration - nowadays referred to as 'resting muscle mechanical activity' (RMMA) - in maintaining body temperature in response to mild cooling;

2. a role for slowed skeletal muscle isometric contraction-relaxation cycle as a mechanism for energy conservation in response to caloric restriction and weight loss and

3. a role for spontaneous physical activity (SPA) - which is contributed importantly by isometric work for posture maintenance and fidgeting behaviours - in adaptive thermogenesis pertaining to weight regulation.

This paper reviews the evidence underlying these proposed roles for isometric work in adaptive thermogenesis and highlights the contention that variability in this neglected component of EE could contribute to human predisposition to obesity.

\section{Resting muscle mechanical activity}

\section{Historical characterization of muscle tone at rest}

Minor tremor or microvibration, the phenomenon that the human body skin surface is constantly vibrating even under conditions of relaxation, underwent considerable characterization in the two decades that followed World War II, in large part due to the pioneering work of Rohracher (7-10). What he coined as 'Mikroschwingung' (or microvibration) was reported to be ever-present from birth to shortly after death and in all parts of the body. Its amplitude was reported to be within a few microns and its frequency to vary according to body site, being lower for larger muscles and higher for small muscles. Subsequent work in animals demonstrated that microvibration frequency is higher in smaller animals and that severing the medulla oblongata or removal of the heart does not eliminate the phenomenon. Microvibration was also found to increase after exercise, and its amplitude to be reduced by muscle relaxants, central nervous system sedatives or ganglion blockers, and to be increased by CNS stimulants. Furthermore, it was observed that microvibration frequency was decreased in a hot environment, increased in the cold, and that such fine tremor is detectable only in warmblooded animals (8). These observations led Rohracher to describe the phenomenon as a normal physiological function involved in the generation of resting muscle tone and that the chemical 'reaction-heat' resulting from muscle microvibration plays a role in maintaining homeothermy $(8,10)$. Three decades later, this notion that invisible muscle vibration helps to maintain body temperature gained further support from the studies of Meigal et al. $(11,12)$ who found that the electromyographic signal increased with cooling prior to visible shivering, leading to the term 'thermoregulatory muscle tone' or 'pre-shivering muscle tone', which they demonstrated was influenced by head and body posture $(11,13)$.

\section{Characterization of resting muscle mechanical activity}

Nowadays, the low-frequency muscle vibration that has over the years been referred to as minor tremor (9), microvibrations (8), muscle sounds (14), invisible shivering, pre-shivering tone or thermoregulatory muscle tone (11-13) is largely attributed to the phenomenon of RMMA. It is detected using specific transducers to record muscle surface oscillations due to mechanical activity of the motor units and measured as mechanomyographic activity $(15,16)$. While it is considered to be the counterpart to the motor unit's electrical activity as measured by electromyography, several workers consider mechanomyographic to be a more sensitive method for examining resting muscle activity than electromyography (16). As the mechanical work of muscle requires energy and must therefore produce heat, and as RMMA refers to the muscle activity involving microvibrations at rest, the heat generated from RMMA can be considered as isometric thermogenesis.

In a series of experiments focused upon understanding the behaviour of RMMA under various conditions in healthy young men, McKay et al. (17) have shown RMMA to be neurally mediated because it disappears with pharmacologic neuromuscular blockade, to increase several folds after vigorous aerobic or resistance exercise and to show proportionately less increase after mild exercise than vigorous exercise $(18,19)$. In more recent years, they also showed that RMMA increases from a minimum at thermoneutral ambient temperature as humans are subjected to mild cooling (20). These findings support the notion that RMMA helps to maintain core temperature at rest, which they argued may account for the consumption of as much as $200 \mathrm{kcal} /$ day under the circumstances of ambient temperature in hospital clothing (21), and hence for substantial heat production to maintain core body temperature at $37{ }^{\circ} \mathrm{C}$ when exposed to an ambient temperature of $\sim 21^{\circ} \mathrm{C}(21)$.

Based upon these aforementioned findings, McKay et al. (20) have postulated a model for defence against cooling whereby RMMA is invoked first at ambient temperatures below thermoneutrality, whereas shivering is invoked as a last resort response with further cooling of the skin or core-cooling. To explain why such a dual system may have evolved, these authors (20) have proposed that in the 


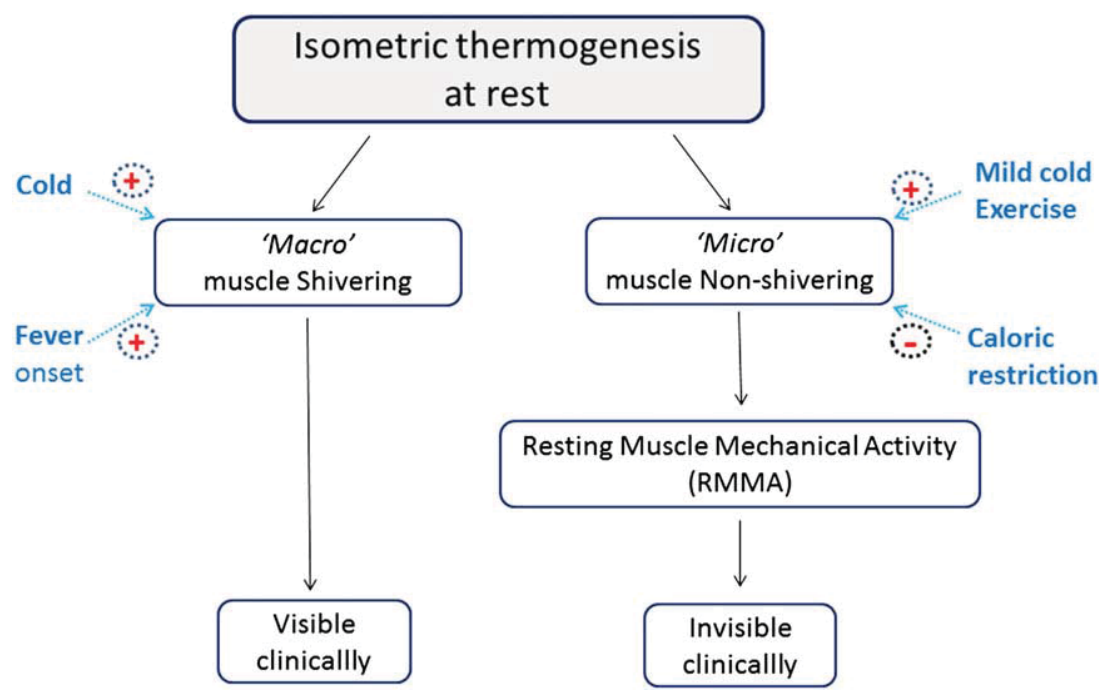

Figure 3 Multiple expressions of isometric thermogenesis at rest. Skeletal muscle shivering, which produces heat in response to cold or the onset of fever, is observed by visual inspection. By contrast, non-shivering thermogenesis in skeletal muscle, due to increased resting muscle mechanical activity is clinically invisible. The latter is increased in response to mild cold $(7,11,20)$ and exercise $(17-19)$ and is postulated to be blunted following prolonged caloric restriction and weight loss (22).

African environment of our ancestors, which is often above thermoneutrality by day and below by night, body temperature could be defended against mild cooling using RMMA. This provides survival benefit by providing temperature stability without the large temperature swings of alternately turning shivering on and off, without the caloric expense of shivering, without the loss of fine motor control that occurs with shivering, and without the involuntary gross

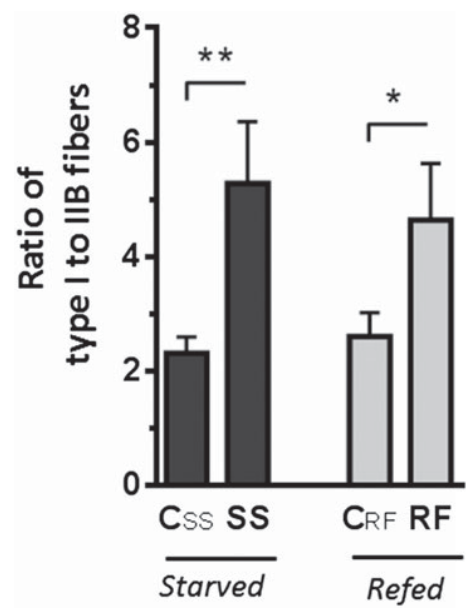

Figure 4 Alterations in skeletal muscle fibre types (ratio of slow type I relative to fast type IIB fibres) in hindlimb gastrocnemius muscle of caloricrestricted (semistarved) and refed rats, and their respective controls. The ratio increases following caloric restriction and persists during the phase of accelerated fat recovery (catch-up fat) during refeeding. SS, semistarved rats; CSS, control of semistarved rats; RF, refed rats; CRF, control of refed rats $(n=8-10)$; Mann-Whitney test; ${ }^{*} P \leq 0.05$; ${ }^{* *} P \leq 0.01$, comparing SS or RF with their respective control. Adapted from Reference $((42))$ visible movement that might give away to the position of the human hiding from a predator'.

\section{Resting muscle mechanical activity as a determinant of resting metabolic rate and adaptive thermogenesis}

While RMMA may have evolved, in part, to maintain core temperature in the face of mild cooling, it seems plausible that RMMA, and its elevation after exercise, may contribute significantly to resting EE. A potential role of RMMA in daily $\mathrm{EE}$ therefore raises two important questions pertaining to energy balance and weight regulation, namely, (i) does variability in RMMA contribute to variability in resting $\mathrm{EE}$ and hence in metabolic predisposition to obesity? and (ii) do changes in RMMA in response to caloric restriction or caloric surplus contribute to adaptive thermogenesis? Bearing in mind that muscle tone has long been clinically (and empirically) assessed by its palpatory quality upon compression by the examiner (i.e. its pliability, firmness or hardness), it is of interest to note that in referring to the many possible mechanisms which might have reduced the basal metabolic rate in the semistarved men of the Classic Minnesota Experiment, Keys et al. (22) pointed out, to quote: By all criteria of ordinary manual examination, there seems to be a reduction in the resting tension or tonus in the voluntary muscles and it is reasonable to suppose that a similar change occurs in the involuntary muscles as well. This might account for some reduction in metabolism beyond that resulting from the simple reduction in muscle mass'. In other words, diminished muscle tone could have contributed to the marked adaptive suppression of 


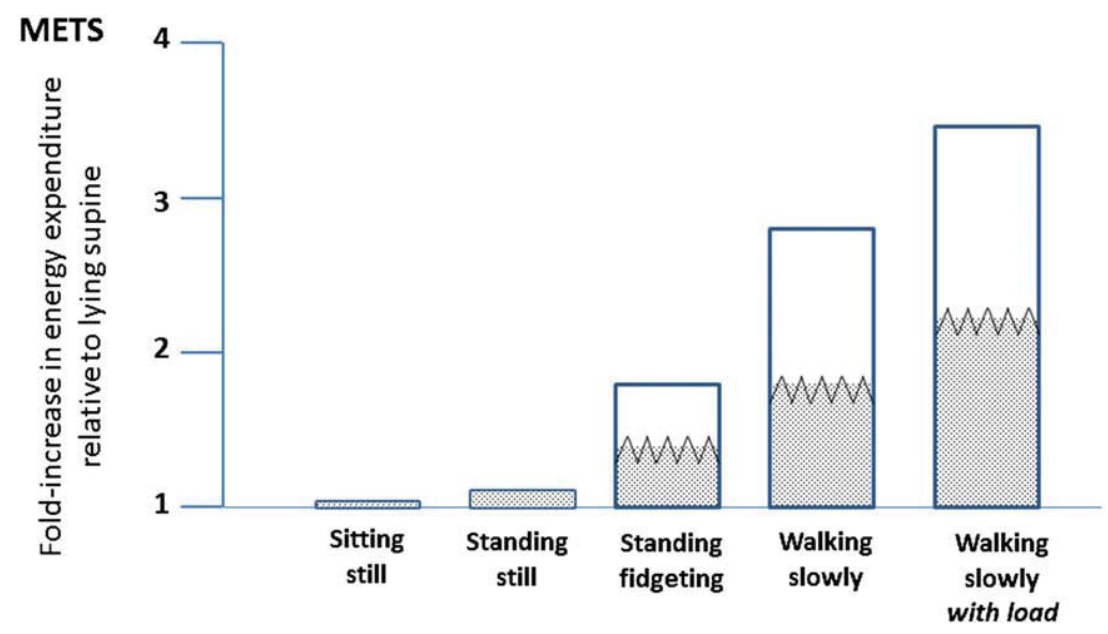

Figure 5 Schematic diagram showing isometric thermogenesis as a component of the magnitude of energy expenditure (EE) in response to various lowlevel physical activities of daily life. The increases in EE for each activity are expressed in relative terms, i.e. as a multiple of EE during lying down (supine) under conditions of basal metabolic rate measurements (defined as $1 \mathrm{MET}$ ). The values for the relative increases in EE for standing ( 1.15 METs), standing with fidgeting ( 2 METs) and walking at low speed (3 METSs) were obtained from indirect calorimetry measurements made by Levine et al. (43). The dotted zone depicts the increasing level of isometric thermogenesis with increasing EE across these low-level physical activities, ranging from sitting still to walking slowly while carrying a heavy load. The zig-zag line above the dotted zone represents the relative uncertainty as to the actual proportion of the increase in EE due to isometric thermogenesis.

thermogenesis (and hence energy conservation) observed in the Minnesota men, albeit in the resting state. The various expressions of isometric thermogenesis at rest, together with the potential effects of mild cold, exercise and caloric restriction on RMMA, are depicted in Fig. 3.

\section{Impact of caloric restriction on skeletal muscle isometric contraction-relaxation cycle}

A slower isometric contraction-relaxation cycle may also play a role in the adaptive supression of thermogenesis observed due to caloric restriction, owing to reduced ATP turnover $(23,24)$ and subsequent energy cost. Indeed, it has long been known that in response to a mild electrically evoked skeletal muscle isometric contraction, the time to peak contraction and time for half-relaxation from the peak are prolonged in malnourished humans who have lost weight (25-29) and that these changes in contractile properties can be induced by caloric restriction in obese patients (30) and in lean rats (31). This diminished rate of isometric contraction-relaxation has been linked to a transition in fibre-type composition from fast-twitch to slow-twitch and appears to be mediated by alterations in thyroid hormone actions. Indeed, the hypothyroid state induced by caloric restriction - just like in clinical hypothyroidism or in response to chemically induced hypothyroidism or thyroid hormone receptor deficiency in animal models - can be linked to a marked shift from fast to slow fibres (32-35). In terms of fuel economy, this state of hypothyroidism-induced shift in favour of slow (type I) fibres could prove beneficial, given evidence that slow-twitch fibres require less ATP per unit of isometric tension than fast-twitch fibres (36-38). Furthermore, a higher energetic efficiency, as may be observed in a hypothyroid state, could also affect the speed of the skeletal muscle contraction-relaxation cycle (39-41).

Further insights into the underlying molecular mechanisms can be derived from recent experiments (42) indicating that in rats showing diminished rates of electrically induced contraction-relaxation during semistarvation and early refeeding, there were substantial alterations in skeletal muscle fibre composition with an increased ratio of slow to fast (I/IIB) fibres (Fig. 4) as well as in muscle expression of deiodinase 1, 2 and 3 - all of which play a role in controlling local thyroid hormone metabolism. In line with these changes, a decreased availability of muscle T3, the primary active thyroid hormone, was also observed. Together, these findings (42) indicate that decreased intracellular availability of T3 may be driving the fast-to-slow fibre transition and diminished rate of the contraction-relaxation cycle, thereby conserving energy during weight loss and weight recovery and contributing to a thrifty metabolic phenotype to aid in the rapid repletion of adipose stores.

\section{Isometric thermogenesis during spontaneous physical activity}

As mentioned in the introduction, isometric work is intertwined with dynamic work, and in many instances, it is essential for the performance of dynamic work, particularly, in terms of postural maintenance in the upright position, thereby allowing walking, running and in fact most daily life physical activities (Fig. 5). While the contribution 


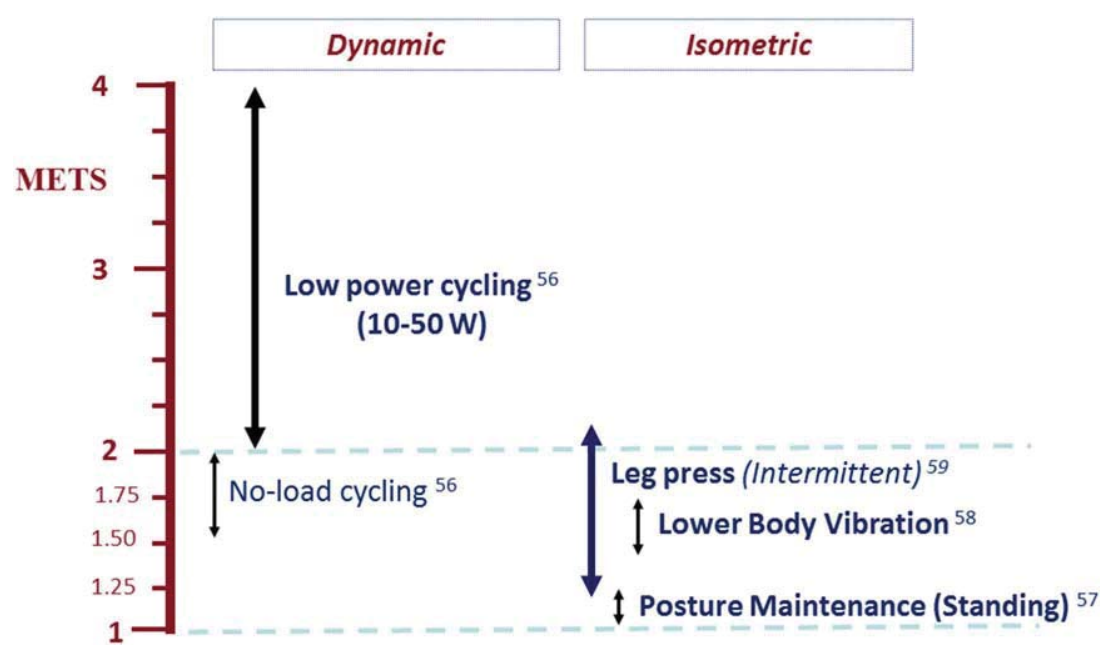

Figure 6 Standardized tests recently developed for assessing human variability in the energy cost of low-level dynamic and isometric physical activities. For each test, the double-headed arrow indicates the range for the measured relative increases in energy expenditure (expressed in METs) across the varying intensity of the physical activity test. The references for these standardized tests are indicated as superscripts.

of isometric thermogenesis to the daily EE associated with such activities is difficult to quantify, it is likely to be of major importance for SPA, i.e. the energy expended on fine movement, muscle tone and what is generally termed 'fidgeting' $(4,43)$. These latter activities, often subconscious, show remarkable individual variability, the behaviour perhaps reflecting differences between individuals' personality and neurochemical make-up $(44,45)$.

Spontaneous physical activity is a component of daily EE that is increasingly recognized as playing an important role in achieving energy balance, and hence in body-weight regulation $(44,45)$. Ravussin et al. (46) have highlighted the potential role of SPA-associated thermogenesis in body-weight regulation by showing that even under the relatively confined conditions of a respiratory chamber, SPA (detected by radar motion sensors) accounts $8-15 \%$ of total daily EE ranging from 100 to $680 \mathrm{kcal} / \mathrm{day}$. Consequent longitudinal studies of Pima Indian men suggested that SPA is a familial trait predictive of both 3 -year weight and fat gain in these men (47), consistent with cross-sectional observations of diminished SPA in obese individuals.

More direct evidence in support of the contribution of changes in SPA to autoregulatory changes EE has been generated through the Biosphere 2 experiment (48), in which eight individuals (men and women) underwent gradual weight loss over 2 years. From the data collected during a subsequent stay in a respiratory chamber, their losses in body weight were found to be accompanied by a markedly lower SPA, which like their diminished daily EE, was found to persist several months after the onset of weight recovery and which could be implicated in their disproportionate regain of body fat relative to lean mass. These findings are therefore consistent with the notion that diminished SPA may contribute significantly to the adaptive suppression of thermogenesis that occurs in response to caloric restriction and weight loss and that drives rapid fat storage during weight regain (49-51).

Similarly, Miller et al. (52), following their 'Gluttony Experiments', postulated that resistance to obesity in some of their subjects could reside in an increased EE associated with simple low-level activities of everyday life, including SPA. Some 30 years later, evidence in support of this hypothesis was presented by Levine et al. (53), who showed that, following 8 weeks of overfeeding $(+1000 \mathrm{kcal} / \mathrm{day})$, more than half of the observed increase in daily EE in their sedentary subjects could be accounted for by increases in activity EE, which the authors referred to as non-exercise activity thermogenesis (NEAT). This increase in NEAT was most predictive of fat gain - which varied considerably amongst the subjects (range: 0.36 to $4.23 \mathrm{~kg}$ ). Owing to the fact that no structured exercise took place, and no changes in either overt physical activity or the thermic effect of meals was observed, increases in NEAT were attributed to increases in low-level SPA (range: -98 to $692 \mathrm{kcal} / \mathrm{day}$ ). However, it is also possible that these increases may, at least in part, be attributed to a decrease in muscle work efficiency, whether voluntary or spontaneous, dynamic or isometric.

Further evidence of the importance of daily low-level isometric thermogenesis in energy balance can be derived from studies indicating that altering posture allocation (i.e. between lying, sitting and standing) - and hence posture-related isometric thermogenesis - can modify EE to impact upon body-weight regulation and health (54). With obese individuals shown to sit for $2.5 \mathrm{~h}$ /day more than their lean counterparts, it has been suggested that should the obese 
replace these $2.5 \mathrm{~h}$ of sitting with an additional $2.5 \mathrm{~h}$ of standing, this posture re-allocation could result in the expenditure of an additional $350 \mathrm{kcal} /$ day (54), sufficient to positively affect body-weight regulation if accumulated over time.

Taken together, the earlier studies suggest that the high degree of heterogeneity in SPA observed between individuals may play a key role in the inter-individual variability that is also observed in terms of total daily EE.

\section{Isometric thermogenesis: a link between adult stature and cardiometabolic risks}

With the recognition that low-intensity physical activity (including SPA) plays an important role in body-weight regulation, with a greater influence on the obesity epidemic than moderate-to-vigorous intensity leisure-time pursuits (55), there is considerable interest for better monitoring, characterizing and promoting of a plethora of low-level physical activities in daily life (e.g. active workstations, standing desks and sitting breaks). Little attention, however, has been directed at assessing how humans vary in the specific energy cost (or efficiency) of performing low-level physical activities, which, in addition to intensity and duration of the physical activity, can also contribute to variability in predisposition to obesity. In search for suitable approaches to characterize human variability in isometric thermogenesis, recent work from our laboratory has characterized the energy cost of several types of low-level physical activities (Fig. 6), including low power cycling (56) and those with a predominantly isometric component, namely, standing posture maintenance (57), acute intermittent side-alternating whole-body vibration across commonly-used vibration frequencies (58) and intermittent leg press exercise (59). The latter was performed in the seated position in an ergonomic and adjustable car seat that was modified to enable continuous assessment of EE with the subject at rest or while exerting low-intensity isometric work; this was achieved by intermittently pressing (for $30 \mathrm{~s} / \mathrm{min}$ ) both legs simultaneously against a press-platform incorporating a weighing scale; the intermittent leg press exercise was performed at five different isometric loads between 5 and $25 \mathrm{~kg}$ force, with the energy cost of this intermittent isometric exercise being determined individually by linear regression (59).

Energy expenditure during the aforementioned intermittent low-intensity isometric leg press increased in parallel to increasing load, by $17-62 \%$ on average (range: 11 to $93 \%$ ) and was thus well within the range of EE observed during daily-life low-level activities. Importantly, using this methodology, inter-individual variability was shown to be several times larger than intra-individual variability assessed on separate days (coefficient of variation of $35 \%$ vs. $12 \%$, respectively). Along this new avenue for research in EE phenotyping for isometric thermogenesis, our preliminary findings (59) that stature, but not weight, is positively associated with isometric thermogenesis raises the possibility that low-isometric thermogenesis could constitute a 'thrifty metabolic' link in the well-documented associations between adult short stature (or leg length) and increased risks for cardiovascular diseases (60), type 2 diabetes (61) and obesity $(62,63)$.

\section{Concluding remarks}

The aforementioned standardized approach to study isometric thermogenesis (in response to intermittent low-intensity isometric workloads), as a complementary approach for EE phenotyping at rest or during dynamic activity, opens up a new avenue for research in EE and metabolic phenotyping. Considering the ubiquitous nature of isometric work, increasing research into the energy costs of this often overlooked variable has implications for research in human energy metabolism, and potential for a better understanding of metabolic predisposition to obesity and cardiometabolic risks.

\section{Conflict of interest statement}

The authors declare that they have no conflicts of interest.

\section{References}

1. Bender DA. Oxford Reference. A Dictionary of Food and Nutrition, 3rd edn. Oxford University Press: Oxford, UK, 2014 On line: http://www.oxfordreference.com/view/10.1093/acref/ 9780199234875.001.0001/acref-9780199234875-e-5441.

2. Cerretelli P, Veicsteinas A, Fumagalli M, Dell'orto L. Energetics of isometric exercise in man. J Appl Physiol 1976; 41: 136-141.

3. Koerhuis CL, van der Heide FM, Hof AL. Energy consumption in static muscle contraction. Eur J Appl Physiol 2003; 88: 588-592. 4. Miller DS. Factors affecting energy expenditure. Proc Nutr Soc 1982; 41: 193-202.

5. Perrault H. Efficiency of movement in health and chronic disease. Clin Invest Med 2006; 29: 117-121.

6. Schafer RC. Body alignment, posture, and gait. In: Clinical Biomechanics: Musculoskeletal Actions and Reactions, 2nd edn Chapter 4. Williams \& Wilkins: Baltimore, Maryland, USA, 1987. 7. Rohracher H. Thermal balance and microvibration. Acta Neuroveg (Wien) 1955; 11: 187-200.

8. Rohracher H. Microvibration, permanent muscle-activity and constancy of body temperature. Percept Mot Skills 1964; 19: 198. 9. Sugano H, Inanaga K. Studies in minor tremor. Jpn J Physiol 1960; 10: 246-257.

10. Pacela AF. Measurement of the body surface physiological tremor or 'microvibration'. Behav Res Meth Instru 1968; 1: 60-70. 11. Meigal AY, Lupandin YV, Hänninen O. Head and body positions affect thermoregulatory tonus in deltoid muscles. J Appl Physiol 1996; 80: 1397-1400.

12. Meigal AY, Oksa J, Hohtola E, Lupandin YV, Rintamäki H. Influence of cold shivering on fine motor control in the upper limb. Acta Physiol Scand 1998; 163: 41-47.

13. Meigal A. Gross and fine neuromuscular performance at cold shivering. Int J Circumpolar Health 2002; 61: 163-172. 
14. Orizio C. Muscle sound: bases for the introduction of a mechanomyographic signal in muscle studies. Crit Rev Biomed Eng 1993; 21: 201-243.

15. Islam MA, Sundaraj K, Ahmad RB, Ahamed NU. Mechanomyogram for muscle function assessment: a review. PLoS One 2013; 8: e58902. DOI: 10.1371/journal.pone.0058902.

16. Cè E, Rampichini S, Esposito F. Novel insights into skeletal muscle function by mechanomyography: from the laboratory to the field. Sport Sci Health 2015; 11: 1-28.

17. McKay WP, Chilibeck PD, Chad KE, Daku BL. Resting mechanomyography after aerobic exercise. Can J Appl Physiol 2004; 29: 743-757.

18. McKay WP, Jacobson P, Chilibeck PD, Daku BL. Effects of graded levels of exercise on ipsilateral and contralateral post-exercise resting rectus femoris mechanomyography. Eur J Appl Physiol 2006; 98: 566-574.

19. McKay WP, Chilibeck PD, Daku BL. Resting mechanomyography before and after resistance exercise. Eur J Appl Physiol 2007; 102: 107-117.

20. McKay WP, Vargo M, Chilibeck PD, Daku BL. Effects of ambient temperature on mechanomyography of resting quadriceps muscle. Appl Physiol Nutr Metab 2013; 38: 227-233.

21. McKay WP, Chilibeck PD, Daku BL, Lett B. Quantifying the mechanical work of resting quadriceps muscle tone. Eur J Appl Physiol 2010; 108: 641-648.

22. Keys A, Brozek J, Henschel A, Mickelsen O, Taylor HL. The Biology of Human Starvation. The University of Minnessota Press: Minneapolis, London, 1950, pp. 338-339.

23. Pichard C, Vaughan C, Struk R, Armstrong RL, Jeejeebhoy KN. Effect of dietary manipulations (fasting, hypocaloric feeding, and subsequent refeeding) on rat muscle energetics as assessed by nuclear magnetic resonance spectroscopy. J Clin Invest 1988; 82: 895-901.

24. Mijan De La Torre A, Madapallimattam A, Cross A, Armstrong RL, Jeejeebhoy KN. Effect of fasting, hypocaloric feeding, and refeeding on the energetics of stimulated rat muscle as assessed by nuclear magnetic resonance spectroscopy. J Clin Invest 1993; 92: 114-121.

25. Lopes J, Russell DM, Whitwell J, Jeejeebhoy KN. Skeletal muscle function in malnutrition. Am J Clin Nutr 1882; 36: 602-610.

26. Russell DM, Prendergast PJ, Darby PL, Garfinkel PE, Whitwell J, Jeejeebhoy KN. A comparison between muscle function and body composition in anorexia nervosa: the effect of refeeding. Am J Clin Nutr 1983; 38: 229-237.

27. Chan ST, McLaughlin SJ, Ponting GA, Biglin J, Dudley HA. Muscle power after glucose-potassium loading in undernourished patients. Br Med J 1986; 293: 1055-1056.

28. Pichard C, Jeejeebhoy KN. Muscle dysfunction in malnourished patients. Q J Med 1988; 69: 1021-1045.

29. Nishio ML, Jeejeebhoy KN. Skeletal muscle relaxation rate after fasting or hypocaloric feeding. J Appl Physiol 1991; 71: 204-209.

30. Russell DM, Leiter LA, Whitwell J, Marliss EB, Jeejeebhoy KN. Skeletal muscle function during hypocaloric diets and fasting: a comparison with standard nutritional assessment parameters. Am J Clin Nutr 1983; 37: 133-138.

31. Russell DM, Atwood HL, Whittaker JS et al. The effect of fasting and hypocaloric diets on the functional and metabolic characteristics of rat gastrocnemius muscle. Clin Sci (Lond) 1984; 67: 185-194.

32. Ianuzzo D, Patel P, Chen V, O’Brien P, Williams C. Thyroidal trophic influence on skeletal muscle myosin. Nature 1977; 270: $74-76$.
33. Wiles CM, Young A, Jones DA, Edwards RH. Muscle relaxation rate, fibre-type composition and energy turnover in hyperand hypo-thyroid patients. Clin Sci (Lond) 1979; 57: 375-384.

34. Johansson C, Lunde PK, Gothe S, Lannergren J, Westerblad H. Isometric force and endurance in skeletal muscle of mice devoid of all known thyroid hormone receptors. J Physiol 2003; 547: 789-796.

35. Simonides WS, van Hardeveld C. Thyroid hormone as a determinant of metabolic and contractile phenotype of skeletal muscle. Thyroid 2008; 18: 205-216.

36. Wendt IR, Gibbs CL. Energy production of rat extensor digitorum longus muscle. Am J Physiol 1973; 224: 1081-1086.

37. Crow MT, Kushmerick MJ. Chemical energetics of slow- and fast-twitch muscles of the mouse. J Gen Physiol 1982; 79: 147-166. 38. Henriksson J. The possible role of skeletal muscle in the adaptation to periods of energy deficiency. Eur J Clin Nutr 1990; 44: $55-64$.

39. Russell DM, Walker PM, Leiter LA et al. Metabolic and structural changes in skeletal muscle during hypocaloric dieting. Am J Clin Nutr 1984; 39: 503-513.

40. Caiozzo VJ, Haddad F. Thyroid hormone: modulation of muscle structure, function, and adaptive responses to mechanical loading. Exerc Sport Sci Rev 1996; 24: 321-361.

41. Everts ME. Effects of thyroid hormone on $\mathrm{Ca} 2+$ efflux and $\mathrm{Ca} 2+$ transport capacity in rat skeletal muscle. Cell Calcium 1990; 11: 343-352.

42. De Andrade PB, Neff LA, Strosova MK et al. Caloric restriction induces energy-sparing alterations in skeletal muscle contraction, fiber composition and local thyroid hormone metabolism that persist during catch-up fat upon refeeding. Front Physiol 2015; 6: 254. DOI: 10.3389/fphys.2015.00254.

43. Levine JA, Schleusner SJ, Jensen MD. Energy expenditure of nonexercise activity. Am J Clin Nutr 2000; 72: 1451-1454.

44. Johannsen DL, Ravussin E. Spontaneous physical activity: relationship between fidgeting and body weight control. Curr Opin Endocrinol Diabetes Obes 2008; 15: 409-415.

45. Dulloo AG, Jacquet J, Montani JP, Schutz Y. Adaptive thermogenesis in human body weight regulation: more of a concept than a measurable entity? Obes Rev 2012; 13(Suppl 2): 105-121.

46. Ravussin E, Lillioja S, Anderson TE et al. Determinants of 24-hour energy expenditure in man: methods and results using a respiratory chamber. J Clin Invest 1986; 78: 1568-1578.

47. Zurlo F, Ferraro RT, Fontvielle AM et al. Spontaneous physical activity and obesity: cross-sectional and longitudinal studies in Pima Indians. Am J Physiol 1992; 263(2 Pt 1): E296-E300.

48. Weyer C, Walford RL, Harper IT et al. Energy metabolism after 2 y of energy restriction: the Biosphere 2 experiment. Am J Clin Nutr 2000; 72: 946-953.

49. Dulloo AG, Jacquet J. Adaptive reduction in basal metabolic rate in response to food deprivation in humans: a role for feedback signals from fat stores. Am J Clin Nutr 1998; 68: 599-606.

50. Carbonnel F, Messing B, Rimbert A, Rongier M, Koziet J, Darmaun D. Energy and protein metabolism during recovery from malnutrition due to nonneoplastic gastrointestinal disease. Am J Clin Nutr 1997; 65: 1517-1523.

51. Dulloo AG, Jacquet J. An adipose-specific control of thermogenesis in body weight regulation. Int J Obes Relat Metab Disord 2001; 25(Suppl 5): S22-S29.

52. Miller DS, Mumford P, Stock MJ. Gluttony. 2. Thermogenesis in overeating man. Am J Clin Nutr 1967; 20: 1223-1229.

53. Levine JA, Eberhardt NL, Jensen MD. Role of nonexercise activity thermogenesis in resistance to fat gain in humans. Science 1999; 283: 212-214. 
54. Levine JA, Lanningham-Foster LM, McCrady SK. Interindividual variation in posture allocation: possible role in human obesity. Science 2005; 307: 584-586.

55. Tudor-Locke C, Schuna J, Frensham L, Proenca M. Changing the way we work: elevating energy expenditure with workstation alternatives. Int J Obes (Lond) 2014; 38: 755-765.

56. Fares EJ, Isacco L, Loonam $\mathrm{C}$ et al. Energy expenditure phenotyping during low physical activity levels: validation of very low power cycling exercise in sedentary humans. Obes Rev 2016; 17(suppl. 2): 79

57. Miles-Chan JL, Sarafian D, Montani JP, Schutz Y, Dulloo A. Heterogeneity in the energy cost of posture maintenance during standing relative to sitting: phenotyping according to magnitude and time-course. PLoS One 2013; 8(5): e65827. DOI: 10.1371/ journal.pone.0065827.

58. Fares EJ, Charrière N, Montani JP, Schutz Y, Dulloo AG, Miles-Chan JL. Energy expenditure and substrate oxidation in response to side-alternating whole body vibration across three commonly-used vibration frequencies. PLoS One 2016; 11(3): e0151552. DOI: 10.1371/journal.pone.0151552.
59. Sarafian D, Miles-Chan JL, Yepuri G, Montani JP, Schutz Y, Dulloo AG. A standardized approach to study human variability in isometric thermogenesis during low-intensity physical activity. Front Physiol 2013; 4: 155. DOI: 10.3389/fphys.2013.00155. 60. Paajanen TA, Oksala NK, Kuukasjärvi P, Karhunen PJ. Short stature is associated with coronary heart disease: a systematic review of the literature and a meta-analysis. Eur Heart J 2010; 31: 1802-1809.

61. Asao K, Kao WH, Baptiste-Roberts K, Bandeen-Roche K, Erlinger TP, Brancati FL. Short stature and the risk of adiposity, insulin resistance, and type 2 diabetes in middle age: the Third National Health and Nutrition Examination Survey (NHANES III), 1988-1994. Diabetes Care 2006; 29: 1632-1637.

62. Hermanussen M, Sunder M, Voigt M, Tresguerres JA. Morbid obesity is associated with short stature. J Pediatr Endocrinol Metab 2005; 18: 647-650.

63. Bosy-Westphal A, Plachta-Danielzik S, Dörhöfer RP, Müller MJ. Short stature and obesity: positive association in adults but inverse association in children and adolescents. Br J Nutr 2009; 102: 453-461. 